\title{
A Predictive Analysis of the Business Environment of Economies along the Belt and Road Using the Fractional-Order Grey Model
}

\author{
Lingling Pei $\mathbb{D}^{1}$ and Jun Liu $\mathbb{D}^{2}$ \\ ${ }^{1}$ School of Business Administration, Zhejiang University of Finance and Economics, Hangzhou 310018, China \\ ${ }^{2}$ School of Economics, Zhejiang University of Finance and Economics, Hangzhou 310018, China \\ Correspondence should be addressed to Jun Liu; liujunzjcj@163.com
}

Received 17 June 2021; Accepted 28 July 2021; Published 3 August 2021

Academic Editor: Lifeng Wu

Copyright (c) 2021 Lingling Pei and Jun Liu. This is an open access article distributed under the Creative Commons Attribution License, which permits unrestricted use, distribution, and reproduction in any medium, provided the original work is properly cited.

\begin{abstract}
This paper determined the optimal order of $\operatorname{FGM}(1,1)$ model through particle swarm optimization algorithm and combined with the World Bank business environment data to predict and analyze the business environment of economies along the Belt and Road. The empirical results show that the $\operatorname{FGM}(1,1)$ model has a good predicting effect on the business environment. In terms of prediction accuracy, the FGM $(1,1)$ model based on particle swarm optimization algorithm to determine the optimal order is significantly better than the traditional GM $(1,1)$ model. The predict results show that the business environment level of economies along the Belt and Road will increase year by year from 2021 to 2022, but the overall level is still relatively low. The main innovation of this paper lies in the introduction of the fractional-order grey model into the predictive analysis of the business environment, which is of great significance to the extension and application of fractional-order models in management and economic systems.
\end{abstract}

\section{Introduction}

In 2013, the Chinese government put forward the Belt and Road initiative, aiming to promote the reasonable flow of factors and effective allocation of resources in the economies along the Belt and Road, improve the level of regional trade and investment facilitation, and explore a new model of international and regional economic cooperation [1]. The Belt and Road initiative has effectively promoted the investment and cooperation between China and countries along the Belt and Road [2]. Lv [3] used the DID method to comprehensively evaluate the investment promotion effect of the Belt and Road initiative and found that the implementation of the Belt and Road initiative significantly promoted the growth of Chinese enterprises' foreign greenfield investment. Previous studies have shown that transnational investment activities of enterprises can bring about multiple effects such as reverse technology spillover, industrial upgrading, and economic growth [4-7]. From the perspective of investment risk, some scholars also pointed out that enterprises face many challenges in the host country's politics, economy, investment policies, and other aspects when carrying out transnational investment activities [8,9]. Due to the significant differences in the development stages, cultural backgrounds, historical traditions, and institutional conditions of the economies along the Belt and Road, when enterprises conduct transnational investment activities in economies along the Belt and Road, they not only face the challenges of political, economic, and other macrolevel risks but also face the test of the host country's business environment.

The term "Business Environment" is derived from the survey of the "Doing Business" project of the International Finance Corporation of the World Bank Group [10]. As an important indicator to measure the quality of different 
business environments, the Business Environment Report issued by the World Bank provides an important reference for investors of various countries to make transnational investment decisions [11]. In view of the importance of the business environment in transnational investment activities, scholars have studied the relationship between the business environment and transnational investment from different perspectives. Corcoran and Gillanders [12] analyzed whether there is any correlation between FDI inflow and the business environment in a country. The empirical results show that there is a strong positive correlation between FDI inflow and the business environment. Based on the panel data of 123 economies in the world from 2009 to 2018, Zhang and Liu [13] empirically analyzed the impact of the business environment on foreign direct investment. The results show that there is a significant positive correlation between the improvement of the host country's business environment and foreign direct investment. Some scholars have also conducted research on the business environment of the economies along the Belt and Road. Based on the OFDI data of Chinese enterprises in 49 representative countries along the Belt and Road from 2007 to 2017, Wang and Zhou [14] investigated the impact of the business environment of the countries along the Belt and Road on the OFDI of Chinese enterprises. It is found that the OFDI with different investment motivations has a heterogeneous preference for the host country's business environment. At present, the existing literature has made a relatively comprehensive exploration on the relationship between the business environment of the host country and FDI, but no scholars have explored the prediction of the business environment. As a supplement to the macroindicators of the institutional environment, the business environment objectively measures the business laws and regulations of various countries and their implementation, which will have a direct impact on the transnational business activities of enterprises. Therefore, using scientific methods to predict the business environment of the economies along the Belt and Road is of great significance for enterprises to reduce the risk of transnational investment and better carry out transnational investment activities.

The grey system theory and prediction model originally proposed by professor Deng can accurately predict the future development trend with "small sample and poor information" data in the real world, which has been widely applied in many fields such as energy, economy, and environment [15]. Several scholars use grey prediction models to predict product sales, customer demand, and development trend in the economic field. For example, Xia and Wong [16] established a seasonal discrete grey prediction model based on cycle truncation accumulation in order to accurately predict inventory data in the apparel retail industry. The problem of seasonality of inventory data and data missing is solved effectively. Nguyen and Tran [17] used GM $(1,1), \operatorname{DGM}(1,1)$, DGM $(2,1)$, and Verhulst models to forecast the tourism demand of
Vietnam's tourism industry and put forward corresponding policy suggestions to the government. Mao et al. [18], based on the relationship between Chinese commercial banks and third-party online payment systems, used the Grey Lotka-Volterra model to quantitatively analyze and predict the impact of commercial banks' online payment systems on the development of third-party online payment systems. Xiao et al. [19] proposed a new grey multivariable coupling model, $\operatorname{CFGM}(1, N)$, to evaluate the coordination degree of China's R \& D system and economic system under the condition of limited information. The results show that this model has better convergence and interpretability. On the basis of unequal accumulation, Tu and Chen [20] proposed an unequal adjacent discrete multivariable grey model. Compared with other models, this model has good predictive performance and algorithm efficiency. Rajesh et al. [21] used the grey prediction model and Markov model based on movement probability to predict the retail elasticity level of the urban retail system and then proposed policies to improve the elasticity level of the urban center. In addition to its application in the economic field, due to its simple modeling results and excellent performance, the grey prediction model is currently widely used in energy and environment fields, such as wind power [22], power consumption [23, 24], high-tech industry [25], natural gas consumption $[26,27]$, and pollution emission $[28,29]$.

The advantage of the GM $(1,1)$ model is that it can deal with grey information and poor data, but the model is mainly applicable to the sequence with strong exponential law and can only describe the monotone change process, and it has a big error in some specific fields. In view of the shortcomings of the traditional GM $(1,1)$ model, Wu et al. [30] first proposed the fractional-order cumulative $\operatorname{GM}(1,1)$ model (FGM $(1,1))$. The matrix perturbation theory was used to explain that the traditional integer-order cumulative generating operator violated the new information priority principle of grey system theory and proved that the smaller the cumulative order, the higher the priority of new information. Through accumulation, the characteristics and laws of integration hidden in the original data can be fully revealed. Later, many scholars used the FGM $(1,1)$ model and the extended model to predict the time series data in different fields, and the error could be effectively reduced by selecting the appropriate fractional order. A large number of examples showed that the prediction accuracy of the FGM $(1,1)$ model and its extended model was significantly higher than that of the traditional grey prediction model [31-37]. $\mathrm{Wu}$ et al. [38] established a new fractional-order prediction model and introduced a fractional cumulative generation matrix to analyze the properties of the model. Yan et al. [39] proposed a grey model with fractionalized Hausdorff derivative to improve the prediction accuracy of the traditional grey model and analyzed the model. The results showed that the model would not be affected by the initial value, and more consideration was given to the principle of new information first. Zhu et al. [40] optimized the initial conditions by introducing the fractional-order weighting 
coefficient. Compared with the old initial conditions in the traditional grey model, the newly optimized initial conditions had a flexible structure and could more effectively capture the dynamic characteristics of the time series data. In addition, in order to further improve the prediction accuracy, the particle swarm optimization algorithm (PSO) is used to estimate the adjustable fractional weighting coefficient and the corresponding time parameters of the initial conditions. Liu et al. [41] established a generalized discrete grey prediction model to predict the total retail sales of consumer goods in China by introducing weighted fractional-order accumulation and discretization errors.

By combining the relevant literature, it can be found that the existing literature has made a relatively comprehensive study on the relationship between the business environment and transnational investment, but no scholars have discussed the prediction of the business environment. In terms of prediction theory and model, the existing grey model for environmental prediction research mainly focuses on the fields of pollution emission and energy consumption and has not involved the prediction research on the business environment. Based on this, this paper makes use of the transnational panel data of the World Bank on the business environment from 2014 to 2020 and uses the FGM $(1,1)$ model to predict and analyze the business environment of 52 economies along the Belt and Road. The innovation lies in the application of the fractional-order grey model in the field of business environment, which broadens the research field of the fractional-order grey model and is of great significance for the expansion of fractional-order models in the field of economic management. The research conclusions are conducive to a clearer understanding of the business environment and future trend of economies along the Belt and Road and provide a reference for enterprises to conduct transnational investment activities in the economies along the Belt and Road.

The rest of this paper is structured as follows: The second part introduces the method of the fractional-order grey model. The third part is the empirical analysis and the discussion of the results, including the determination of the optimal order of the FGM $(1,1)$ model, the comparison of the prediction accuracy between the GM $(1,1)$ model and FGM $(1,1)$ model, and the prediction results of the FGM (1, 1) model. The fourth part is the conclusion.

\section{Methods}

2.1. A Brief Introduction to the Basic Fractional-Order Grey Model

Definition 1. assume the nonnegative sequence

$$
X^{(0)}=\left(x^{(0)}(1), x^{(0)}(2), \ldots, x^{(0)}(n)\right)
$$

as the original sequence and let

$$
X^{(r)}(k)=\sum_{i=1}^{k}\left(\begin{array}{c}
k-i+r-1 \\
k-i
\end{array}\right) x^{(0)}(i), \quad k=1,2, \ldots, n
$$

be the $r(0<r<1)$-order accumulated generating operator $(r-A G O)$. We set $\quad\left(\begin{array}{c}r-1 \\ 0\end{array}\right)=1, \quad\left(\begin{array}{c}k-1 \\ k\end{array}\right)=0$, $k=1,2, \ldots, n$, and

$$
\left(\begin{array}{c}
k-i+r-1 \\
k-i
\end{array}\right)=\frac{(r+k-i-1)(r+k-i-2), \ldots,(r+1) r}{(k-i) !},
$$

where $\quad X^{(r)}=\left(x^{(r)}(1), x^{(r)}(2), \ldots, x^{(r)}(n)\right) \quad$ is the $r(0<r<1)$-order accumulated generation sequence.

Definition 2. Let the nonnegative sequence

$$
X^{(0)}=\left(x^{(0)}(1), x^{(0)}(2), \ldots, x^{(0)}(n)\right) .
$$

Then, let

$$
\alpha^{(1)} x^{(1-r)}(k)=x^{(1-r)}(k)-x^{(1-r)}(k-1)
$$

be the $r(0<r<1)$-order inverse accumulated generating operator $(r-\mathrm{IAGO})$, and

$$
\begin{aligned}
\alpha^{(r)} X^{(0)} & =\alpha^{(1)} X^{(1-r)} \\
& =\left(\alpha^{(1)} x^{(1-r)}(1), \alpha^{(1)} x^{(1-r)}(2), \ldots, \alpha^{(1)} x^{(1-r)}(n)\right)
\end{aligned}
$$

is the $r$-order inverse accumulated generation sequence.

Definition 3. Let the nonnegative sequence

$$
X^{(0)}=\left(x^{(0)}(1), x^{(0)}(2), \ldots, x^{(0)}(n)\right) .
$$

The $r(0<r<1)$-order accumulated generation sequence is

$$
X^{(r)}=\left(x^{(r)}(1), x^{(r)}(2), \ldots, x^{(r)}(n)\right)
$$

Thus,

$$
x^{(r)}(k)-x^{(r)}(k-1)+a z^{(r)}(k)=b
$$

is the basic form of the fractional-order $\operatorname{GM}(1,1)$ model (FGM model), where $z^{(r)}(k)=\left(x^{(r)}(k)+x^{(r)}(k-1)\right)$ $/ 2, k=2,3, \ldots, n$, when $r=1$, and it transforms into the traditional GM $(1,1)$ model.

The least square method is used to estimate the parameters of equation (9):

$$
\left[\begin{array}{l}
\hat{a} \\
\widehat{b}
\end{array}\right]=\left(B^{T} B\right)^{-1} B^{T} Y
$$

where 


$$
\begin{aligned}
& Y=\left[\begin{array}{c}
x^{(r)}(2)-x^{(r)}(1) \\
x^{(r)}(3)-x^{(r)}(2) \\
\vdots \\
x^{(r)}(n)-x^{(r)}(n-1)
\end{array}\right], \\
& B=\left[\begin{array}{cc}
-z^{(r)}(2) & 1 \\
-z^{(r)}(3) & 1 \\
\vdots & \vdots \\
-z^{(r)}(n) & 1
\end{array}\right]
\end{aligned}
$$

According to equation (9), the corresponding whitening equation is

$$
\frac{\mathrm{d} x^{(r)}(t)}{\mathrm{d} t}+a x^{(r)}(t)=b .
$$

The time response formula of the abovementioned equation is

$$
\hat{x}^{(r)}(k+1)=\left[x^{(0)}(1)-\frac{\widehat{b}}{\hat{a}}\right] e^{-\widehat{a} k}+\frac{\widehat{b}}{\widehat{a}}, \quad k=1,2, \ldots, n .
$$

\subsection{Optimization of the Fractional Order $r$ Based on Particle} Swarm Optimization (PSO) Algorithm. In this paper, particle swarm optimization algorithm is used to optimize the order of the FGM $(1,1)$ model, in order to minimize the error. Mean Percentage Error (MAPE) is generally used as the main criterion. This algorithm was first proposed by Kennedy and Eberhart [42] in 1995 and originated from the study of simulating the random hunting and predation behavior of birds. The main steps of particle swarm optimization are as follows:

(1) The particle swarm was initialized. The population size was $m=50$ particles, the search space was $D$ dimension, the learning factor $c_{1}=c_{2}=1.2$ was set, and the inertia weight was $w=0.8$. The particle dimension of the FGM $(1,1)$ model is set as 1 dimension, which represents the solving parameter $r$. The positions and velocities of the particles in the initialized particle swarm are as follows:

$$
\begin{aligned}
\mathbf{X} & =\left(x_{1}, x_{2}, \ldots, x_{j}\right), \\
\mathbf{V} & =\left(v_{1}, v_{2}, \ldots, v_{j}\right), \\
j & =1,2, \ldots, m .
\end{aligned}
$$

(2) calculate the fitness value of each particle according to the fitness algorithm. In this paper, the goal is to minimize the MAPE value, and the mathematical form is expressed as

$$
\underset{r}{\operatorname{MAPE}} \underset{\min }{\operatorname{Min}}(F(r))=\frac{1}{n} \sum_{i=1}^{n}\left|\frac{x^{(0)}(j)-\hat{x}^{(0)}(j)}{x^{(0)}(j)}\right| \times 100 \%,
$$

$$
\left\{\begin{array}{c}
Y . \hat{a} \widehat{b}]=\left(B^{T} B\right)^{-1} B^{T} Y, \\
Y=\left[\begin{array}{c}
x^{(r)}(2)-x^{(r)}(1) \\
x^{(r)}(3)-x^{(r)}(2) \\
\vdots \\
x^{(r)}(n)-x^{(r)}(n-1)
\end{array}\right], \\
B=\left[\begin{array}{cc}
-z^{(r)}(2) & 1 \\
-z^{(r)}(3) & 1 \\
\vdots & \vdots \\
-z^{(r)}(n) & 1
\end{array}\right], \\
\widehat{x}^{(r)}(k+1)=\left[x^{(0)}(1)-\frac{\hat{b}}{\hat{a}}\right] e^{-\hat{a} k}+\frac{\hat{b}}{\hat{a}}, k=1,2, \ldots, n, \\
\hat{x}^{(0)}(k)=\left\{\left[\hat{x}^{(r)}(1)\right]^{(-r)},\left[\hat{x}^{(r)}(1)\right]^{(-r)}, \ldots,\left[\hat{x}^{(r)}(1)\right]^{(-r)}\right\} .
\end{array}\right.
$$

(3) use equation (15) to calculate the fitness value of each particle. We compare the current fitness value of each particle with the fitness value of the optimal position $p_{\text {best }}$ experienced by the individual and the global optimal position $g_{\text {best }}$ and update $p_{\text {best }}$ and $g_{\text {best }}$.

(4) optimize the velocity and position, update the velocity and position of the particle according to equations (17) and (18), and limit the velocity within $V_{\max }$.

$v_{j+1}=w v_{j}^{d}+c_{1} r_{1}\left(p_{\text {best }}-x_{j}^{d}\right)+c_{2} r_{2}\left(g_{\text {best }}-x_{j}^{d}\right)$,

$x_{j+1}^{d}=x_{j}^{d}+v_{j}^{d}$

where $j=1,2, \ldots, m, d=1,2, \ldots, D: r_{1}, r_{2}$ are random numbers; $x_{j}^{d}, v_{j}^{d}$ are the current position and velocity of the $j_{\text {th }}$ particle, respectively; and $p_{\text {best }}$ and $g_{\text {best }}$ are, respectively, the optimal position experienced by the $j_{\text {th }}$ particle and the optimal position experienced by the whole population.

(5) Judging the termination condition: if the termination condition (MAPE value is small enough or 
reaches the maximum number of cycles) is met, we set the maximum number of iterations $T_{\max }=500$ to terminate the algorithm; otherwise, we return to step 2.

2.3. The Modelling Steps of the FGM $(1,1)$ Based on PSO Algorithm. The modeling steps of the $r$-order accumulated grey prediction model based on PSO algorithm are as follows:

Step 1: the $r$-order accumulated generation sequence is calculated $X^{(r)}=\left(x^{(r)}(1), x^{(r)}(2), \ldots, x^{(r)}(n)\right)$

Step 2: the least square method is used to estimate the parameters $\left[\begin{array}{l}\widehat{a} \\ \widehat{b}\end{array}\right]$

Step 3: the optimal order $r_{\text {best }}$ is obtained based on particle swarm optimization algorithm

Step 4: the predicted value is obtained according to the time response formula of the FGM $(1,1)$ model

Step 5: finally, the abovepredicted value is reduced to $r$ order to get the final predicted value $\widehat{X}^{(0)}$

The specific flow chart is shown in Figure 1.

In order to compare the accuracy of the model and verify the validity and reliability of the model, the MAPE value is selected in this paper to calculate the prediction error $[23,26,43]$. The smaller the MAPE value is, the higher the accuracy of the model is, which can be found using the following formula:

$$
\text { MAPE }=\frac{1}{n} \sum_{i=1}^{n}\left|\frac{e(i)}{x^{(0)}(i)}\right| \times 100 \% .
$$

In formula (19), $e(i)=x^{(0)}(i)-\hat{x}^{(0)}(i), x^{(0)}(i)$ and $\hat{x}^{(0)}(i)$ represent the actual value and predicted value, respectively.

\section{Empirical Analysis}

3.1. Data Collection. The Belt and Road is an open international regional economic cooperation initiative, taking the Eurasian continent as the main region and gradually extending to relevant countries and regions, without defining clear geographical boundaries. Referring to the research of Guo et al. [44] and combined with data availability, the research objects set in this paper include 52 countries along the Belt and Road. In terms of data on the environment of doing business, the World Bank has issued a yearly report on the environment of doing business since the end of 2003. The latest edition is "Doing Business 2020," which was released in October 2019. Starting from different stages of daily business operations, the report makes a comprehensive evaluation and horizontal comparison of the level of business environment within each economy, which has gained widespread attention worldwide. The ranking of ease of doing business and the reform suggestions put forward by the World Bank's Doing Business Report have not only become an important reference tool for many countries to force domestic reforms, attract capital inflows, and promote economic development but also provide a reference for enterprises to make decisions on transnational investment activities. Because some sample countries lack business environment data before 2014, this paper obtained the original data of the business environment scores of 52 countries along the Belt and Road from 2014 to 2020 by referring to the World Bank's Doing Business database (https://www.doingbusiness.org/) and conducted empirical modeling analysis.

3.2. The Optimal Order Value of the FGM $(1,1)$ Model. The main advantage of the FGM $(1,1)$ model is that it can effectively reduce the prediction error by selecting appropriate fractional order, so as to obtain more accurate prediction results. In this paper, particle swarm optimization algorithm is used to solve the optimal order of the FGM $(1,1)$ model to minimize the prediction error. The calculation results of the optimal order of the FGM $(1,1)$ model based on particle swarm optimization algorithm are shown in Table 1.

According to the particle swarm optimization given in Sections 2.2 and 2.3 and the optimization steps of the fractional-order grey model based on this algorithm, we take Poland as an example to observe the convergence process of particle swarm optimization. The specific convergence of MAPE is shown in Figure 2. For comparison, the cases of $r=0.1,0.2,0.3,0.4,0.5,0.6,0.7,0.8,0.9$, and 1 are listed. The actual and predicted values are shown in Table 2, and the error comparison is shown in Table 3. It can be seen that the particle swarm optimization algorithm can quickly find the optimal solution and the optimal parameters of fractional order, so as to effectively reduce the prediction error and improve the prediction accuracy of the model, which indicates that the FGM $(1,1)$ model based on particle swarm optimization algorithm has good reliability and stability.

\subsection{Comparison of Prediction Accuracy between the GM $(1,1)$} Model and FGM $(1,1)$ Model. In the process of empirical analysis, this paper divides the original data of the business environment scores of 52 countries along the Belt and Road from 2014 to 2020 into the training set and the testing set. Among them, the business environment score data from 2014 to 2019 are used as the training set and the business environment score data from 2020 are used as the testing set. According to the MAPE value of the GM $(1,1)$ model and FGM $(1,1)$ model in the training set and testing set, the prediction ability of the two models in the business environment was compared. The specific MAPE values calculated by the GM $(1,1)$ model and FGM $(1,1)$ model in the training set and testing set are shown in Tables 4 and 5 . Figures 3 and 4 visually show the difference in accuracy between the GM $(1,1)$ model and the FGM $(1,1)$ model in predicting the business environment.

According to the empirical results in Tables 4 and 5, it can be found that, in the training stage, the maximum value of MAPE of the GM $(1,1)$ model is $5.37 \%$, the minimum value is $0.2 \%$, and the average value is $1.46 \%$. The maximum value of MAPE in the FGM $(1,1)$ model was $5.26 \%$, the minimum value was $0.11 \%$, and the average value was $0.96 \%$. 


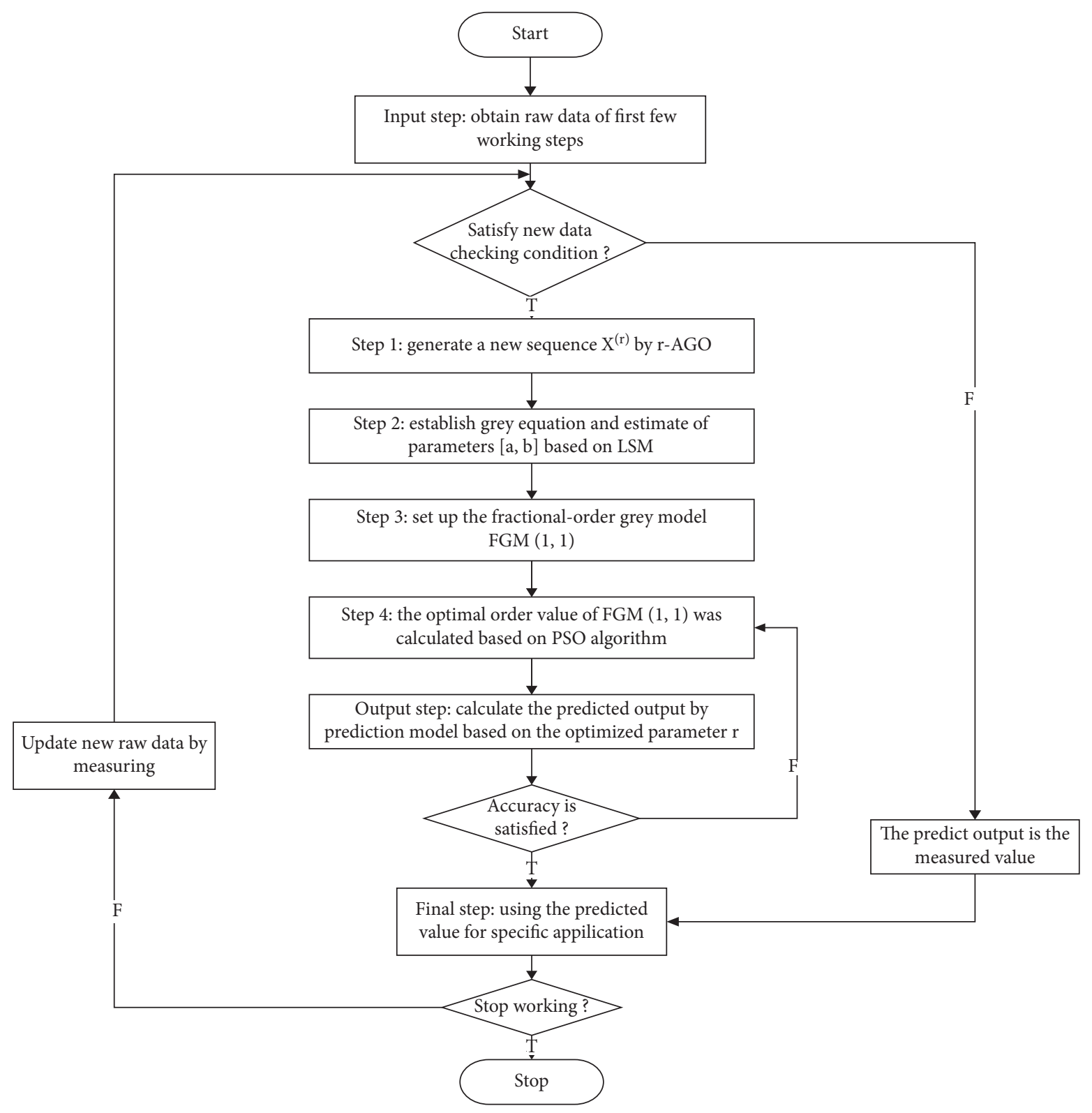

FIgURE 1: The calculation steps of the $\operatorname{FGM}(1,1)$ model based on PSO algorithm.

TABLE 1: Optimal order value of FGM $(1,1)$.

\begin{tabular}{lr}
\hline Country & $r$ \\
\hline Singapore & 0.01 \\
Georgia & 0.03 \\
Latvia & 0.09 \\
Estonia & 0.92 \\
Lithuania & 0.86 \\
Poland & 0.79 \\
Macedonia & 0.15 \\
Czech & 0.92 \\
Israel & 0.02 \\
Slovakia & 0.85 \\
Bulgaria & 0.06 \\
Slovenia & 0.75 \\
Turkey & 0.04 \\
\hline
\end{tabular}


TABle 1: Continued.

\begin{tabular}{|c|c|}
\hline Country & $r$ \\
\hline Russia & 0.83 \\
\hline Qatar & 0.01 \\
\hline Hungary & 0.88 \\
\hline Montenegro & 0.09 \\
\hline Oman & 0.06 \\
\hline Bahrain & 0.94 \\
\hline Romania & 0.19 \\
\hline Croatia & 0.86 \\
\hline Armenia & 0.94 \\
\hline Belarus & 0.25 \\
\hline Mongolia & 0.95 \\
\hline Serbia & 0.55 \\
\hline Moldova & 0.72 \\
\hline Vietnam & 0.08 \\
\hline Kazakhstan & 0.53 \\
\hline Kuwait & 0.01 \\
\hline Indonesia & 0.003 \\
\hline Bosnia & 0.84 \\
\hline China & 1.00 \\
\hline Sri Lanka & 0.02 \\
\hline Ukraine & 0.99 \\
\hline Egypt & 0.08 \\
\hline Lebanon & 0.05 \\
\hline Nepal & 0.20 \\
\hline Kyrgyzstan & 0.03 \\
\hline Brunei & 0.07 \\
\hline Jordan & 0.02 \\
\hline Albania & 0.02 \\
\hline Maldives & 0.05 \\
\hline Iran & 0.05 \\
\hline Cambodia & 0.01 \\
\hline Uzbekistan & 0.44 \\
\hline Iraq & 0.05 \\
\hline Syria & 0.08 \\
\hline Bangladesh & 0.05 \\
\hline Lao PDR & 0.93 \\
\hline East Timor & 0.06 \\
\hline Myanmar & 1.00 \\
\hline Afghanistan & 0.13 \\
\hline
\end{tabular}

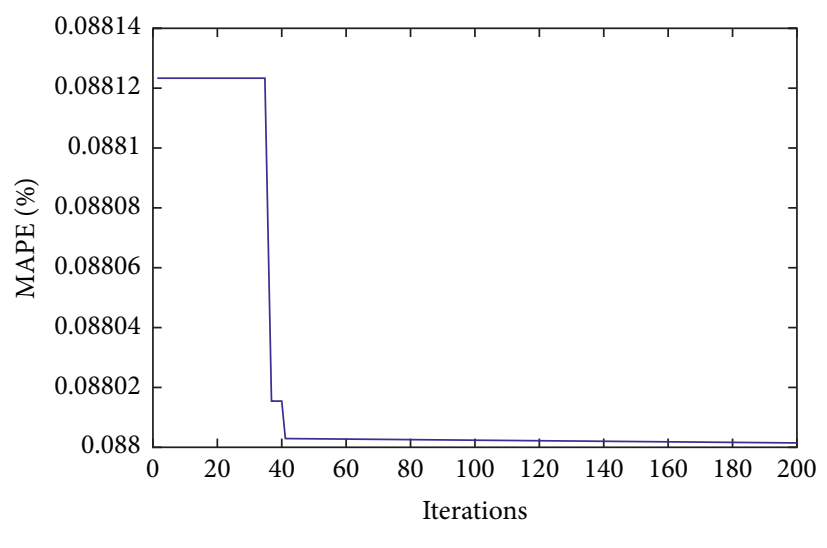

— The value of MAPE

FIgURE 2: Optimization process of FGM $(1,1)$ based on PSO algorithm (an example of Poland). 
TABLe 2: Actual values and predicted values (an example of Poland).

\begin{tabular}{cccccccccccc}
\hline Time & Actual value & $r=0.1$ & $r=0.2$ & $r=0.3$ & $r=0.4$ & $r=0.5$ & $r=0.6$ & $r=0.7$ & $r=0.8$ & $r=0.9$ & $r=1$ \\
\hline 2014 & 73.60 & 73.60 & 73.60 & 73.60 & 73.60 & 73.60 & 73.60 & 73.60 & 73.60 & 73.60 & 73.60 \\
2015 & 74.10 & 74.63 & 74.29 & 73.99 & 73.77 & 73.65 & 73.66 & 73.82 & 74.15 & 74.67 & 75.40 \\
2016 & 76.90 & 76.22 & 76.43 & 76.62 & 76.79 & 76.92 & 76.98 & 76.95 & 76.81 & 76.52 & 76.04 \\
2017 & 77.70 & 77.08 & 77.46 & 77.78 & 78.02 & 78.16 & 78.17 & 78.05 & 77.77 & 77.32 & 76.69 \\
2018 & 77.90 & 77.35 & 77.53 & 77.69 & 77.81 & 77.87 & 77.87 & 77.81 & 77.70 & 77.54 & 77.35 \\
2019 & 76.90 & 77.21 & 76.98 & 76.79 & 76.66 & 76.59 & 76.61 & 76.73 & 76.98 & 77.40 & 78.01 \\
\hline
\end{tabular}

TABLE 3: Error comparison (an example of Poland).

\begin{tabular}{lcccccccccc}
\hline \multirow{2}{*}{ APE (\%) } & & \multicolumn{3}{c}{$r$} & \multicolumn{2}{c}{$r$} & & \\
& $r=0.1$ & $r=0.2$ & $r=0.3$ & $r=0.4$ & $r=0.5$ & $r=0.6$ & $r=0.7$ & $r=0.8$ & $r=0.9$ & $r=1$ \\
\hline & 0.00 & 0.00 & 0.00 & 0.00 & 0.00 & 0.00 & 0.00 & 0.00 & 0.00 & 0.00 \\
& 0.72 & 0.25 & 0.15 & 0.45 & 0.60 & 0.59 & 0.38 & 0.06 & 0.76 \\
MAPE (\%) & 0.89 & 0.61 & 0.36 & 0.14 & 0.02 & 0.10 & 0.06 & 0.12 & 0.50 & 1.75 \\
& 0.79 & 0.31 & 0.10 & 0.41 & 0.59 & 0.61 & 0.45 & 0.09 & 0.49 & 1.29 \\
& 0.71 & 0.47 & 0.27 & 0.12 & 0.04 & 0.03 & 0.11 & 0.26 & 0.46 & 0.71 \\
& 0.41 & 0.10 & 0.14 & 0.32 & 0.40 & 0.38 & 0.22 & 0.11 & 0.65 & 1.44 \\
& 0.70 & 0.35 & 0.20 & 0.29 & 0.33 & 0.29 & 0.24 & 0.13 & 0.57 & 1.26 \\
\hline
\end{tabular}

TABLE 4: MAPE values of the training set.

\begin{tabular}{|c|c|c|}
\hline \multicolumn{3}{|c|}{ Training set } \\
\hline Model & GM $(1,1)$ & FGM $(1,1)$ \\
\hline Country & MAPE (\%) & MAPE (\%) \\
\hline Singapore & 0.55 & 0.37 \\
\hline Georgia & 1.21 & 0.96 \\
\hline Latvia & 0.53 & 0.26 \\
\hline Estonia & 0.67 & 0.21 \\
\hline Lithuania & 0.82 & 0.38 \\
\hline Poland & 1.26 & 0.09 \\
\hline Macedonia & 1.03 & 0.31 \\
\hline Czech & 0.64 & 0.13 \\
\hline Israel & 0.22 & 0.19 \\
\hline Slovakia & 1.29 & 0.51 \\
\hline Bulgaria & 0.78 & 0.58 \\
\hline Slovenia & 1.60 & 0.44 \\
\hline Turkey & 1.48 & 1.30 \\
\hline Russia & 1.36 & 0.45 \\
\hline Qatar & 0.82 & 0.68 \\
\hline Hungary & 0.79 & 0.37 \\
\hline Montenegro & 0.82 & 0.51 \\
\hline Oman & 0.57 & 0.50 \\
\hline Bahrain & 0.69 & 0.62 \\
\hline Romania & 1.46 & 0.35 \\
\hline Croatia & 1.15 & 0.33 \\
\hline Armenia & 0.45 & 0.21 \\
\hline Belarus & 1.17 & 0.40 \\
\hline Mongolia & 0.43 & 0.19 \\
\hline Serbia & 3.08 & 1.47 \\
\hline Moldova & 1.78 & 0.52 \\
\hline Vietnam & 0.52 & 0.45 \\
\hline Kazakhstan & 2.82 & 1.14 \\
\hline Kuwait & 0.74 & 0.48 \\
\hline Indonesia & 0.61 & 0.53 \\
\hline Bosnia & 1.23 & 0.32 \\
\hline China & 2.49 & 2.49 \\
\hline Sri Lanka & 1.45 & 0.96 \\
\hline
\end{tabular}

TABLE 4: Continued.

\begin{tabular}{lcc}
\hline Model & $\begin{array}{c}\text { Training set } \\
\text { GM }(1,1)\end{array}$ & FGM $(1,1)$ \\
Country & MAPE (\%) & MAPE (\%) \\
\hline Ukraine & 0.40 & 0.38 \\
Egypt & 3.33 & 1.98 \\
Lebanon & 2.04 & 1.66 \\
Nepal & 1.00 & 0.99 \\
Kyrgyzstan & 1.15 & 1.04 \\
Brunei & 1.68 & 1.40 \\
Jordan & 1.64 & 1.07 \\
Albania & 2.66 & 2.57 \\
Maldives & 2.36 & 1.79 \\
Iran & 1.98 & 1.44 \\
Cambodia & 0.34 & 0.22 \\
Uzbekistan & 3.02 & 1.76 \\
Iraq & 2.39 & 1.73 \\
Syria & 1.98 & 1.50 \\
Bangladesh & 2.64 & 1.76 \\
Lao PDR & 0.70 & 0.28 \\
East Timor & 4.49 & 4.07 \\
Myanmar & 0.20 & 0.20 \\
Afghanistan & 5.37 & 5.26 \\
\hline
\end{tabular}

In the testing stage, the maximum value of MAPE of the GM $(1,1)$ model was $10.64 \%$, the minimum value was $0.05 \%$, and the average value was $3.19 \%$. The maximum value of MAPE in the FGM $(1,1)$ model was $8.41 \%$, the minimum value was $0.05 \%$, and the average value was $1.95 \%$. The empirical results show that both the GM $(1,1)$ model and FGM $(1,1)$ model have good applicability and accuracy in predicting the business environment, but the FGM $(1,1)$ model is more accurate in predicting results. The MAPE value of the FGM $(1,1)$ model was less than $10 \%$, and the average MAPE value of the FGM $(1,1)$ model was lower than that of the GM $(1,1)$ model in both the training stage and the testing stage. 
TABLE 5: MAPE values of the testing set.

\begin{tabular}{|c|c|c|}
\hline \multicolumn{3}{|c|}{ Testing set } \\
\hline Model & GM $(1,1)$ & $\operatorname{FGM}(1,1)$ \\
\hline Country & MAPE (\%) & MAPE (\%) \\
\hline Singapore & 0.99 & 0.68 \\
\hline Georgia & 0.81 & 1.97 \\
\hline Latvia & 1.19 & 0.52 \\
\hline Estonia & 1.51 & 0.13 \\
\hline Lithuania & 1.52 & 1.10 \\
\hline Poland & 2.98 & 0.93 \\
\hline Macedonia & 2.85 & 0.71 \\
\hline Czech & 1.17 & 0.51 \\
\hline Israel & 1.40 & 1.89 \\
\hline Slovakia & 2.08 & 0.79 \\
\hline Bulgaria & 0.55 & 0.58 \\
\hline Slovenia & 3.34 & 0.84 \\
\hline Turkey & 1.94 & 2.44 \\
\hline Russia & 2.61 & 0.59 \\
\hline Qatar & 4.24 & 0.32 \\
\hline Hungary & 2.08 & 0.28 \\
\hline Montenegro & 2.82 & 0.31 \\
\hline Oman & 0.47 & 1.40 \\
\hline Bahrain & 7.02 & 5.96 \\
\hline Romania & 1.30 & 2.45 \\
\hline Croatia & 1.78 & 1.10 \\
\hline Armenia & 0.54 & 0.80 \\
\hline Belarus & 4.79 & 0.45 \\
\hline Mongolia & 1.94 & 0.81 \\
\hline Serbia & 4.23 & 1.49 \\
\hline Moldova & 1.82 & 2.99 \\
\hline Vietnam & 0.95 & 0.33 \\
\hline Kazakhstan & 5.55 & 0.17 \\
\hline Kuwait & 6.92 & 4.38 \\
\hline Indonesia & 0.86 & 0.19 \\
\hline Bosnia & 2.71 & 0.37 \\
\hline China & 4.58 & 4.58 \\
\hline Sri Lanka & 1.28 & 8.41 \\
\hline Ukraine & 1.40 & 1.33 \\
\hline Egypt & 6.36 & 0.37 \\
\hline Lebanon & 3.57 & 0.05 \\
\hline Nepal & 6.03 & 4.11 \\
\hline Kyrgyzstan & 1.65 & 1.65 \\
\hline Brunei & 5.58 & 5.37 \\
\hline Jordan & 10.64 & 6.97 \\
\hline Albania & 2.54 & 3.35 \\
\hline Maldives & 3.06 & 2.21 \\
\hline Iran & 1.83 & 3.12 \\
\hline Cambodia & 0.05 & 0.78 \\
\hline Uzbekistan & 4.94 & 1.70 \\
\hline Iraq & 2.15 & 1.62 \\
\hline Syria & 5.92 & 1.90 \\
\hline Bangladesh & 8.67 & 0.44 \\
\hline Lao PDR & 0.52 & 1.61 \\
\hline East Timor & 7.48 & 0.89 \\
\hline Myanmar & 6.32 & 6.16 \\
\hline Afghanistan & 6.75 & 5.60 \\
\hline
\end{tabular}

Figures 3 and 4 visually show the difference in prediction accuracy between the GM $(1,1)$ model and the FGM $(1,1)$ model. Compared with the traditional GM $(1,1)$ model, the FGM $(1,1)$ model has better prediction ability in terms of business environment. Therefore, this paper chooses to predict and analyze the business environment of 52 economies along the Belt and Road based on the FGM $(1,1)$ model.

3.4. The Predicted Results of the FGM (1, 1) Model. According to the abovementioned empirical results, the FGM $(1,1)$ model has a good prediction effect in both the training set and the testing set. Based on this, this paper uses the FGM $(1,1)$ model to predict the business environment scores and rankings of 52 economies along the Belt and Road in 2021 and 2022. The specific predicted results are shown in Tables 6 and 7.

As can be seen from the predicted values of the business environment in Tables 6 and 7, the business environment level of economies along the "Belt and Road" is uneven, and there are great differences among different economies. Specific analysis can be carried out from the following aspects:

(1) In terms of the specific score of the business environment, according to the prediction results of the FGM $(1,1)$ model, among the 52 economies along the Belt and Road, countries with a score of business environment above 80 in 2021 include Georgia, Singapore, Turkey, Lithuania, and Estonia and countries with scores below 60 include Nepal, Cambodia, Lebanon, Maldives, Laos, Afghanistan, Iraq, Myanmar, Bangladesh, Syria, and Timor, while the scores of other countries were between 60 and 80 . Business environment score was over 80 in 2022, including Georgia, Turkey, Singapore, Brunei, and China, and below 60 points, including Cambodia, Afghanistan, Maldives, Lebanon, Laos, Bangladesh, Iraq, Brunei, East Timor, and Syria, and the rest is between 60 to 80 points. According to the World Bank's Doing Business 2020 report, the No. 1 economy is New Zealand, with a score of 86.8 . Among the 52 economies along the Belt and Road, most of the sample countries' business environment scores are between 60 and 80 points, indicating that their overall level needs to be improved. In terms of business environment ranking, according to the prediction results of the FGM $(1,1)$ model, among the 52 economies along the Belt and Road, the top five economies in 2021 are Georgia, Singapore, Turkey, Lithuania, and Estonia and the bottom five economies are Iraq, Myanmar, Bangladesh, Syria, and East Timor. The top five economies in 2022 are Georgia, Turkey, Singapore, Brunei, and China, while the bottom five are Iraq, Bangladesh, Myanmar, East Timor, and Syria.

(2) In terms of changes in the overall level of the business environment, according to the predicted results of the FGM $(1,1)$ model, the average level of the business environment in 52 economies along the Belt and Road will increase year by year from 2021 to 2022 , but the increase is slow and the overall level is still low. The forecast average score for 2021 and 


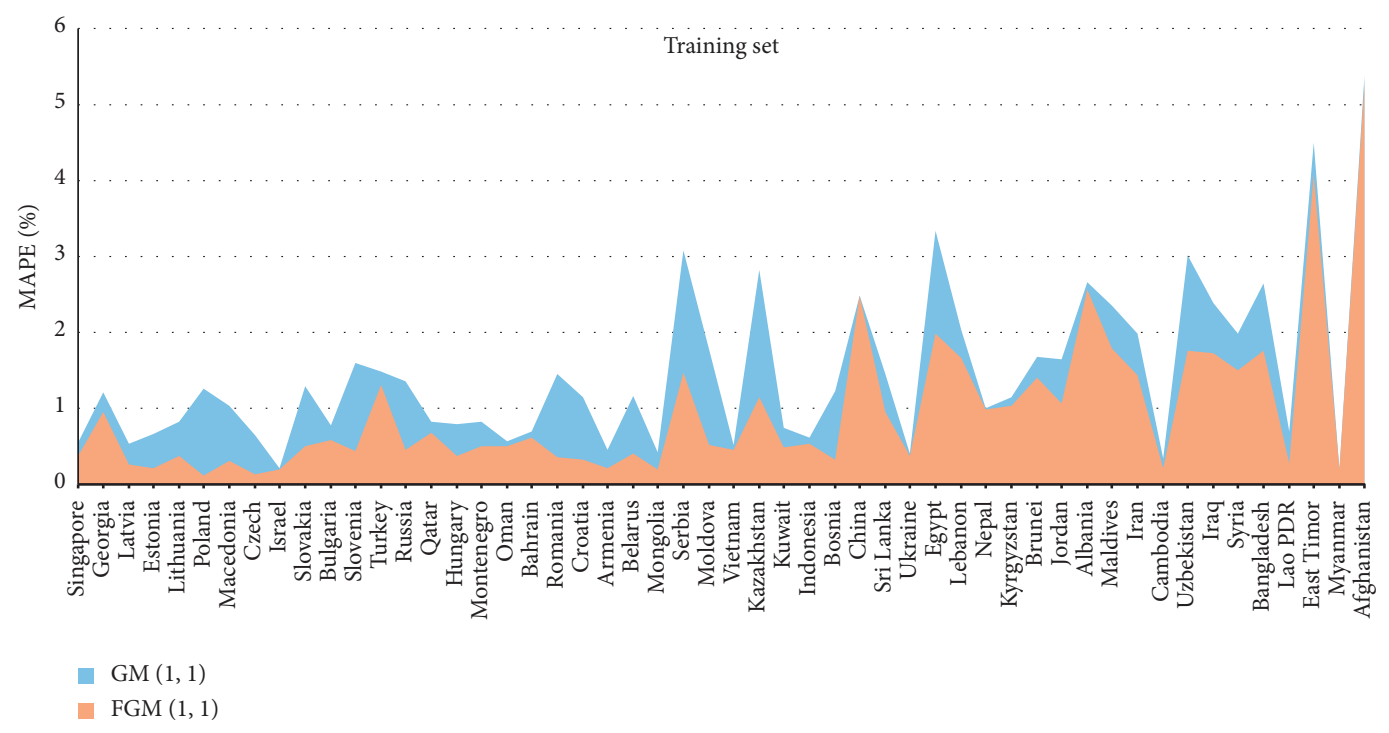

FIgURE 3: MAPE comparison between $\operatorname{GM}(1,1)$ and FGM $(1,1)$ in the training set.

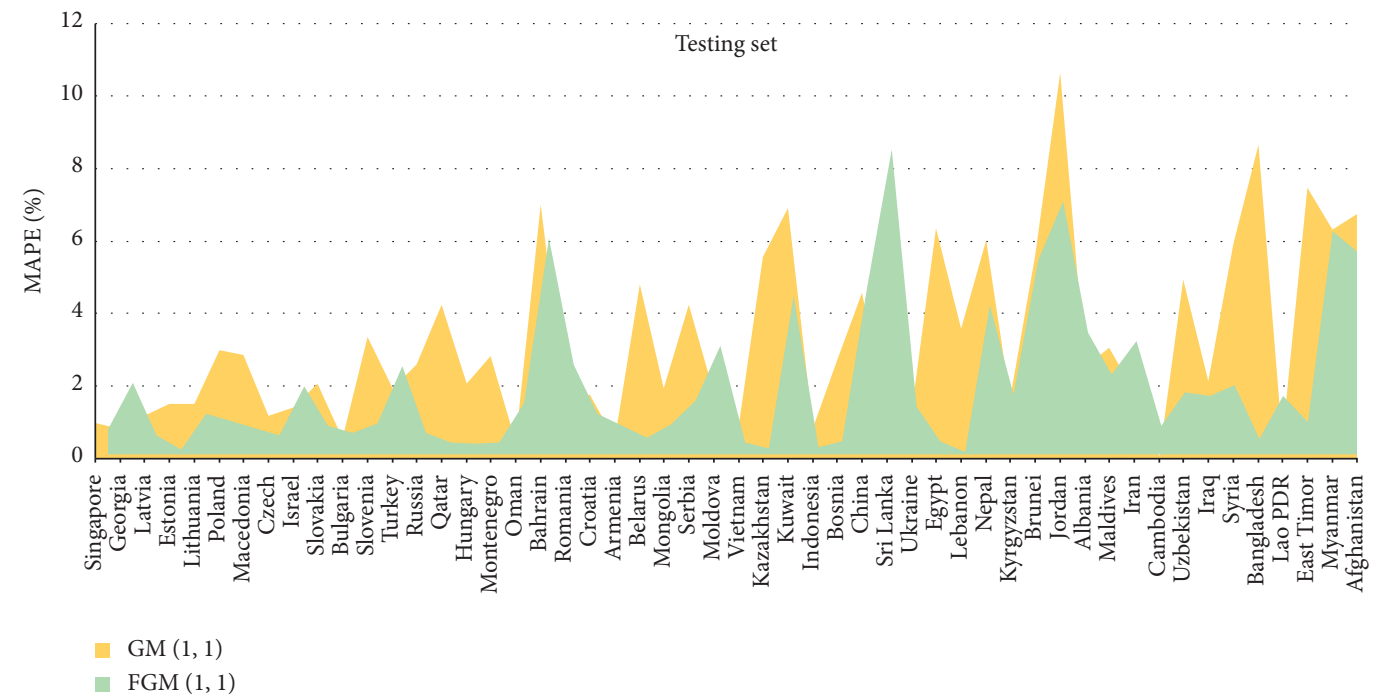

Figure 4: MAPE comparison between $\operatorname{GM}(1,1)$ and $\operatorname{FGM}(1,1)$ in the testing set.

2022 is 68.30 and 69.17, respectively. According to the prediction results of the FGM $(1,1)$ model, among the 52 economies along the Belt and Road, economies with an upward trend in business environment scores in 2021 and 2022 include Georgia, Turkey, Singapore, Brunei, Armenia, Indonesia, Ukraine, Kyrgyzstan, Vietnam, Qatar, Albania, Mongolia, Sri Lanka, Egypt, Iran, Cambodia, Afghanistan, Maldives, Iraq, and East Timor and economies with a downward trend in business environment scores in 2021 and 2022 include Lithuania, Estonia, Latvia, Macedonia, Russia, Czech, Slovakia, Slovenia, Serbia, Hungary, Poland,
Croatia, Romania, Bulgaria, Moldova, Uzbekistan, Bosnia, Lebanon, and Syria. Brunei, Turkey, Afghanistan, Iran, and Georgia are the top five countries in terms of improvement in the business environment in 2021. The top five countries with a decline in the level of the business environment in 2021 are Moldova, Bahrain, Nepal, Romania, and Myanmar. Jordan, Turkey, Brunei, Afghanistan, and Kuwait are the top five countries in terms of improvement in the business environment in 2022. The top five countries with a decline in the level of the business environment in 2021 are Poland, Moldova, Romania, Slovenia, and Serbia. 
TABLE 6: Predicted score and ranking for 2021.

\begin{tabular}{|c|c|c|}
\hline Ranking & Country & Score \\
\hline 1 & Georgia & 86.99 \\
\hline 2 & Singapore & 86.90 \\
\hline 3 & Turkey & 83.25 \\
\hline 4 & Lithuania & 80.32 \\
\hline 5 & Estonia & 80.06 \\
\hline 6 & Macedonia & 79.78 \\
\hline 7 & Kazakhstan & 79.70 \\
\hline 8 & Latvia & 79.64 \\
\hline 9 & Brunei & 78.03 \\
\hline 10 & Russia & 77.78 \\
\hline 11 & China & 77.50 \\
\hline 12 & Israel & 75.97 \\
\hline 13 & Czech & 75.39 \\
\hline 14 & Slovenia & 74.97 \\
\hline 15 & Armenia & 74.82 \\
\hline 16 & Belarus & 74.48 \\
\hline 17 & Slovakia & 74.37 \\
\hline 18 & Poland & 74.23 \\
\hline 19 & Montenegro & 74.17 \\
\hline 20 & Serbia & 74.10 \\
\hline 21 & Hungary & 73.11 \\
\hline 22 & Ukraine & 72.98 \\
\hline 23 & Indonesia & 72.70 \\
\hline 24 & Bahrain & 72.68 \\
\hline 25 & Croatia & 72.38 \\
\hline 26 & Vietnam & 71.42 \\
\hline 27 & Bulgaria & 71.25 \\
\hline 28 & Moldova & 71.07 \\
\hline 29 & Kyrgyzstan & 70.41 \\
\hline 30 & Romania & 70.37 \\
\hline 31 & Oman & 69.26 \\
\hline 32 & Uzbekistan & 68.99 \\
\hline 33 & Albania & 68.98 \\
\hline 34 & Mongolia & 68.84 \\
\hline 35 & Qatar & 68.76 \\
\hline 36 & Jordan & 68.33 \\
\hline 37 & Kuwait & 67.27 \\
\hline 38 & Bosnia & 64.67 \\
\hline 39 & Sri Lanka & 64.35 \\
\hline 40 & Egypt & 62.55 \\
\hline 41 & Iran & 62.44 \\
\hline 42 & Nepal & 59.91 \\
\hline 43 & Cambodia & 54.60 \\
\hline 44 & Lebanon & 53.92 \\
\hline 45 & Maldives & 53.60 \\
\hline 46 & Lao PDR & 50.46 \\
\hline 47 & Afghanistan & 50.32 \\
\hline 48 & Iraq & 45.99 \\
\hline 49 & Myanmar & 44.25 \\
\hline 50 & Bangladesh & 44.04 \\
\hline 51 & Syria & 39.77 \\
\hline 52 & East Timor & 39.65 \\
\hline
\end{tabular}

TABLE 7: Predicted score and ranking for 2022.

\begin{tabular}{|c|c|c|}
\hline Ranking & Country & Score \\
\hline 1 & Georgia & 89.04 \\
\hline 2 & Turkey & 88.99 \\
\hline 3 & Singapore & 87.88 \\
\hline 4 & Brunei & 82.63 \\
\hline 5 & China & 80.81 \\
\hline 6 & Lithuania & 79.78 \\
\hline 7 & Kazakhstan & 79.58 \\
\hline 8 & Estonia & 79.51 \\
\hline 9 & Latvia & 79.19 \\
\hline 10 & Macedonia & 79.04 \\
\hline 11 & Russia & 77.62 \\
\hline 12 & Israel & 76.38 \\
\hline 13 & Armenia & 75.62 \\
\hline 14 & Indonesia & 75.31 \\
\hline 15 & Ukraine & 74.88 \\
\hline 16 & Czech & 74.78 \\
\hline 17 & Bahrain & 74.39 \\
\hline 18 & Jordan & 74.25 \\
\hline 19 & Montenegro & 74.11 \\
\hline 20 & Belarus & 73.98 \\
\hline 21 & Slovenia & 73.81 \\
\hline 22 & Slovakia & 73.56 \\
\hline 23 & Kyrgyzstan & 73.30 \\
\hline 24 & Serbia & 73.25 \\
\hline 25 & Hungary & 72.88 \\
\hline 26 & Vietnam & 72.60 \\
\hline 27 & Poland & 72.52 \\
\hline 28 & Croatia & 71.80 \\
\hline 29 & Kuwait & 71.36 \\
\hline 30 & Qatar & 71.01 \\
\hline 31 & Bulgaria & 70.90 \\
\hline 32 & Albania & 69.69 \\
\hline 33 & Moldova & 69.68 \\
\hline 34 & Oman & 69.33 \\
\hline 35 & Mongolia & 69.26 \\
\hline 36 & Romania & 69.17 \\
\hline 37 & Uzbekistan & 68.82 \\
\hline 38 & Sri Lanka & 66.23 \\
\hline 39 & Egypt & 66.09 \\
\hline 40 & Iran & 65.17 \\
\hline 41 & Bosnia & 64.03 \\
\hline 42 & Nepal & 60.02 \\
\hline 43 & Cambodia & 55.15 \\
\hline 44 & Afghanistan & 54.73 \\
\hline 45 & Maldives & 53.87 \\
\hline 46 & Lebanon & 53.75 \\
\hline 47 & Lao PDR & 50.58 \\
\hline 48 & Iraq & 47.02 \\
\hline 49 & Bangladesh & 45.63 \\
\hline 50 & Myanmar & 44.65 \\
\hline 51 & East Timor & 39.70 \\
\hline 52 & Syria & 39.37 \\
\hline
\end{tabular}




\section{Conclusions}

Based on the fractional-order grey model, this paper makes a predict analysis on the business environment of 52 economies along the Belt and Road by using the business environment data of the World Bank from 2014 to 2020. The main conclusions are as follows:

(1) The GM $(1,1)$ model and FGM $(1,1)$ model both have good applicability and accuracy in predicting the business environment, but the FGM $(1,1)$ model is more accurate in predicting results. The empirical results show that the MAPE values of the FGM $(1,1)$ model in both the training set and the testing set are less than $10 \%$, indicating that the prediction results of the business environment of economies along the Belt and Road based on the FGM $(1,1)$ model have good robustness. Meanwhile, the average MAPE values of the FGM $(1,1)$ model is lower than that of the GM $(1,1)$ model, indicating that the FGM $(1,1)$ model has better predictive ability in terms of business environment compared with the traditional GM $(1,1)$ model.

(2) There are significant differences in the level of business environment among different economies along the Belt and Road. Countries such as Georgia, Singapore, Turkey, Lithuania, and Estonia are at the forefront of the world's business environment, while Nepal, Cambodia, Lebanon, Maldives, and Laos have much room for improvement. Most other countries are in the middle. The overall level of the business environment of the economies along the Belt and Road is still low, but it will improve year by year. There are significant differences in the trend and degree of change of the business environment in different economies along the Belt and Road. In terms of changing trends, the economies showing an upward trend in the business environment in 2021 and 2022 include Georgia, Turkey, and Singapore, while the economies showing a downward trend include Lithuania, Estonia, and Latvia. In terms of the range of change, countries with big increases in the level of the business environment in 2021 include Brunei, Turkey, and Afghanistan. Countries with big declines in the level of the business environment in 2021 include Moldova, Bahrain, and Nepal. Countries with big increases in the level of the business environment in 2022 include Jordan, Turkey, and Brunei. Countries with big declines in the level of the business environment in 2022 include Poland, Moldova, and Romania.

\section{Data Availability}

The business environment score data used to support the findings of this study are available through the World Bank Doing Business database (https://www.doingbusiness.org/).

\section{Conflicts of Interest}

The authors declare that the research was conducted in the absence of any conflicts of interest.

\section{Acknowledgments}

This research was supported by the Humanities and Social Science Research Fund of the Ministry of Education of China (Grant no. 18YJC630130).

\section{References}

[1] R. Z. Yang and Q. Wei, "Research on international direct investment rules and China's plan under the belt and road initiative," Intertrade, vol. 4, pp. 38-44, 2018.

[2] K. P. B. Cullinane, P. T.-W. Lee, Z. Yang, and Z.-H. Hu, "Editorial: China's belt and road initiative," Transportation Research Part E: Logistics and Transportation Review, vol. 117, pp. 1-4, 2018.

[3] Y. Lv, Y. Lu, S. B. Wu, and Y. Wang, "The effect of the belt and road initiative on firms' OFDI: evidence from China's greenfield investment," Economic Research Journal, vol. 54, no. 9, pp. 187-201, 2019.

[4] L. Branstetter, "Is foreign direct investment a channel of knowledge spillovers? evidence from Japan's FDI in the United States," Journal of International Economics, vol. 68, no. 2, pp. 325-344, 2006.

[5] A. J. Hijzen, I. Tomohiko, and T. Yasuyuki, The Effects of Multinational Production on Domestic Performance: Evidence from Japanese Firms, Research Institute of Economy, Trade and Industry (RIETI), Tokyo, Japan, 2007.

[6] J. E. Haskel, S. C. Pereira, and M. J. Slaughter, "Does inward foreign direct investment boost the productivity of domestic firms?" Review of Economics and Statistics, vol. 89, no. 3, pp. 482-496, 2007.

[7] L.-S. Lau, C.-K. Choong, and Y.-K. Eng, "Investigation of the environmental kuznets curve for carbon emissions in Malaysia: do foreign direct investment and trade matter?" Energy Policy, vol. 68, pp. 490-497, 2014.

[8] P. J. Buckley, L. J. Clegg, A. R. Cross, X. Liu, H. Voss, and P. Zheng, "The determinants of Chinese outward foreign direct investment," Journal of International Business Studies, vol. 38, no. 4, pp. 499-518, 2007.

[9] K. Hayakawa, F. Kimura, and H.-H. Lee, "How does country risk matter for foreign direct investment?" The Developing Economies, vol. 51, no. 1, pp. 60-78, 2013.

[10] P. X. Luo, The World Bank's Doing Business Assessment: Methodology, Rules and Casesp. 1, 1st edition, Yilin Press, Nanjing, China, 2020.

[11] Z.-X. Wang, W.-Q. Lou, and L.-L. Pei, "Evaluation of the business environment of participating countries of the Belt and Road Initiative," Technological and Economic Development of Economy, vol. 26, no. 6, pp. 1339-1365, 2020.

[12] A. Corcoran and R. Gillanders, "Foreign direct investment and the ease of doing business," Review of World Economics, vol. 151, no. 1, pp. 103-126, 2015.

[13] Y. W. Zhang and L. B. Liu, "Does the improvement of business environment promote foreign direct investment?" International Business, vol. 1, pp. 59-68, 2020. 
[14] Z. X. Wang and Q. Zhou, "How business environment affects Chinese enterprises' OFDI to countries along "the belt and road"," Collected Essays on Finance and Economics, vol. 9, pp. 42-52, 2019.

[15] S. Liu, Y. Yang, N. Xie, and J. Forrest, "New progress of grey system theory in the new millennium," Grey Systems: Theory and Application, vol. 6, no. 1, pp. 2-31, 2016.

[16] M. Xia and W. K. Wong, "A seasonal discrete grey forecasting model for fashion retailing," Knowledge-Based Systems, vol. 57, pp. 119-126, 2014.

[17] N. T. Nguyen and T. T. Tran, "Optimizing mathematical parameters of grey system theory: an empirical forecasting case of Vietnamese tourism," Neural Computing and Applications, vol. 31, no. 2, pp. 1075-1089, 2017.

[18] S. H. Mao, M. Zhu, X. P. Wang, and X. P. Xiao, "Grey-Lotka-Volterra model for the competition and cooperation between third-party online payment systems and online banking in china," Applied Soft Computing, vol. 95, 2020.

[19] Q. Xiao, M. Shan, M. Gao, X. Xiao, and H. Guo, "Evaluation of the coordination between China's technology and economy using a grey multivariate coupling model," Technological and Economic Development of Economy, vol. 27, no. 1, pp. 24-44, 2020.

[20] L. Tu and Y. Chen, "An unequal adjacent grey forecasting air pollution urban model," Applied Mathematical Modelling, vol. 99, pp. 260-275, 2021.

[21] R. Rajesh, A. K. Agariya, and C. Rajendran, "Predicting resilience in retailing using grey theory and moving probability based markov models," Journal of Retailing and Consumer Services, vol. 62, 2021.

[22] J. Xia, X. Ma, W. Q. Wu, B. L. Huang, and W. P. Li, “Application of a new information priority accumulated grey model with time power to predict short-term wind turbine capacity," Journal of Cleaner Production, vol. 244, 2020.

[23] S. Ding, K. W. Hipel, and Y.-G. Dang, "Forecasting China's electricity consumption using a new grey prediction model," Energy, vol. 149, pp. 314-328, 2018.

[24] Z.-X. Wang, Q. Li, and L.-L. Pei, "A seasonal GM(1,1) model for forecasting the electricity consumption of the primary economic sectors," Energy, vol. 154, pp. 522-534, 2018.

[25] H.-H. Zheng, Q. Li, and Z.-X. Wang, "Predicting the capital intensity of the new energy industry in China using a new hybrid grey model," Computers \& Industrial Engineering, vol. 126, pp. 507-515, 2018.

[26] W. Wu, X. Ma, B. Zeng, W. Lv, Y. Wang, and W. Li, “A novel Grey Bernoulli model for short-term natural gas consumption forecasting," Applied Mathematical Modelling, vol. 84, pp. 393-404, 2020.

[27] Z.-X. Wang and Q. Li, "Modelling the nonlinear relationship between $\mathrm{CO}_{2}$ emissions and economic growth using a PSO algorithm-based grey verhulst model," Journal of Cleaner Production, vol. 207, pp. 214-224, 2019.

[28] Z. X. Wang and Y. Q. Jv, "A non-linear systematic grey model for forecasting the industrial economy-energy-environment system," Technological Forecasting and Social Change, vol. 167, 2021.

[29] P.-P. Xiong, W.-J. Yan, G.-Z. Wang, and L.-L. Pei, "Grey extended prediction model based on IRLS and its application on smog pollution," Applied Soft Computing, vol. 80, pp. 797-809, 2019.

[30] L. Wu, S. Liu, L. Yao, S. Yan, and D. Liu, "Grey system model with the fractional order accumulation," Communications in Nonlinear Science and Numerical Simulation, vol. 18, no. 7, pp. 1775-1785, 2013.
[31] L. Wu, N. Li, and Y. Yang, "Prediction of air quality indicators for the Beijing-Tianjin-Hebei region," Journal of Cleaner Production, vol. 196, pp. 682-687, 2018.

[32] H. J. Chen, Y. Z. Tong, and L. F. Wu, "Forecast of energy consumption based on FGM $(1,1)$ model," Mathematical Problems in Engineering, vol. 43, 2021.

[33] S. H. Mao, Y. X. Kang, Y. H. Zhang, X. P. Xiao, and H. M. Zhu, "Fractional grey model based on non-singular exponential kernel and its application in the prediction of electronic waste precious metal content," ISA Transactions, vol. 43, 2020.

[34] W. L. Xie, C. X. Liu, W. Z. Wu, W. D. Li, and C. Liu, "Continuous grey model with conformable fractional derivative," Chaos, Solitons \& Fractals, vol. 139, 2020.

[35] C. L. Zheng, W. Z. Wu, W. L. Xie, and Q. Li, "A MFO-based conformable fractional nonhomogeneous grey bernoulli model for natural gas production and consumption forecasting," Applied Soft Computing, vol. 99, 2021.

[36] N. Li, J. L. Wang, L. F. Wu, and Y. M. Bentley, "Predicting monthly natural gas production in china using a novel grey seasonal model with particle swarm optimization," Energy, vol. 215, 2021.

[37] C. Liu, W. Z. Wu, W. L. Xie, and J. Zhang, “Application of a novel fractional grey prediction model with time power term to predict the electricity consumption of India and China," Chaos, Solitons \& Fractals, vol. 141, 2020.

[38] W. Q. Wu, X. Ma, B. Zeng, Y. Wang, and W. Cai, “Application of the novel fractional grey model FAGMO $(1,1) \mathrm{k}$ ) to predict China's nuclear energy consumption," Energy, vol. 165, pp. 223-234, 2018.

[39] C. Yan, L. F. Wu, L. Y. Liu, and Z. Kai, "Fractional Hausdorff grey model and its properties," Chaos, Solitons \& Fractals, vol. 138, 2020.

[40] X. Y. Zhu, Y. G. Dang, and S. Ding, "Using a self-adaptive grey fractional weighted model to forecast jiangsu's electricity consumption in China," Energy, vol. 190, 2020.

[41] C. Liu, W. L. Xie, W. Z. Wu, and H. Zhu, "Predicting Chinese total retail sales of consumer goods by employing an extended discrete grey polynomial model," Engineering Applications of Artificial Intelligence, vol. 102, 2021.

[42] J. Kennedy and R. Eberhart, "Particle-swarm-optimization," in Proceedings of IEEE International Conference on Neural Networks, pp. 1942-1948, Perth, Australia, December 1995.

[43] C. D. Lewis, Industrial and Business Forecasting Methods, Butterworth scientific, London, UK, 1982.

[44] Y. Guo and C. S. Xu, "Meetings between high-ranking officials and kroute," Journal of International Trade, vol. 2, pp. 26-36, 2016. 